\title{
Transport and magnetic properties of $\mathrm{Bi}(\mathrm{Pb}) 2212$ superconducting ceramics doped by low rate of potassium
}

\author{
K. Belala ${ }^{1, *}$, A. Galluzzi ${ }^{2,3}$, M.F. Mosbah ${ }^{1,4}$, M. Polichetti ${ }^{2,3}$ \\ ${ }^{1}$ Material Sciences and Applications Research Unit, Physics Department, Constantine 1 University, \\ B.P. 325 Route d'Ain El Bey, Constantine, 25017, Algeria \\ ${ }^{2}$ Department of Physics ‘E.R. Caianiello’ University of Salerno, Via Giovanni Paolo II, 132, Fisciano (Salerno), I-84084, Italy \\ ${ }^{3}$ CNR-SPIN Salerno, Via Giovanni Paolo II, 123, Fisciano (Salerno), I-84084, Italy \\ ${ }^{4}$ National Polytecnic School of Constantine, Nouvelle Ville Universitaire Ali Mendjeli-BP $75^{\circ}$ RP Ali Mendjeli-Constantine, \\ 25017, Algeria
}

\begin{abstract}
Samples of $\mathrm{Bi}_{1.5} \mathrm{~Pb}_{0.5}\left(\mathrm{Sr}_{1.8-\mathrm{x}} \mathrm{K}_{\mathrm{x}}\right) \mathrm{CaCu}_{2} \mathrm{O}_{8+\mathrm{d}}$ and $\mathrm{Bi}_{1.5} \mathrm{~Pb}_{0.5} \mathrm{Sr}_{1.8} \mathrm{CaCu}_{2} \mathrm{O}_{8+\mathrm{d}} \mathrm{K}_{\mathrm{x}}$ have been prepared from powders of carbonates and primary oxides using the solid state reaction method and compared in this study. In the first case, potassium (K) is substituted in the strontium ( $\mathrm{Sr}$ ) site. In the second one, $\mathrm{K}$ is added. A part of the paper is devoted to discuss the results obtained by X-ray diffraction (XRD) analysis and scanning electron microscope (SEM) observations of ( $\mathrm{Bi}, \mathrm{Pb})_{2} \mathrm{Sr}_{1.8} \mathrm{CaCu}_{2} \mathrm{O}_{8+\mathrm{d}} \mathrm{sam}$ ples doped by potassium to provide additional microstructural information related to the doping method. These analyses are supplemented by resistivity and magnetic measurements. Results show how the rate of doping by potassium affects transport and magnetic properties of $\mathrm{Bi}(\mathrm{Pb}) 2212$ phase. The critical current density $\left(\mathrm{J}_{\mathrm{c}}\right)$ is improved using the two methods and it reaches a double value by the addition of $\mathrm{K}$ as compared to the undoped sample.
\end{abstract}

Keywords: ceramics; superconductors; transport properties; magnetic properties

\section{Introduction}

One of the most fascinating manifestations of quantum mechanics is superconductivity. It is used in many fields: scientific research, nuclear fusion, nuclear magnetic resonance medical imaging, storage of electrical energy and in transport (trains with magnetic levitation but also magneto-hydrodynamic propulsion). It is characterized by two remarkable properties: zero resistance and expulsion of magnetic field (Meissner effect). The discovery of high critical temperature (HTSC) superconductors by J.G. Bednorz and K.A. Müller in 1986 [1], allowed the transition of technologies based on low critical temperature superconductors to HTSC superconductors and extend the applications of superconducting materials. Bismuth-based compounds have the general formula $\mathrm{Bi}_{2} \mathrm{Sr}_{2} \mathrm{Ca}_{\mathrm{n}-1} \mathrm{Cu}_{\mathrm{n}} \mathrm{O}_{4+2 \mathrm{n}+\mathrm{d}}$ with $1 \leqslant \mathrm{n} \leqslant 3$ (Bi2201-Bi2212-Bi2223) [2-5]. The role

*E-mail: ka.az501@yahoo.fr of bismuth substitution by lead in the phase Bi2212 is to increase the $T_{c}$ and the critical current density $\left(\mathrm{J}_{\mathrm{c}}\right)$. Lead $(\mathrm{Pb})$ changes density holes in the charge reservoir constituted by the $\mathrm{BiO}$ layer. The effect of lead can thus serve as moderator or amplifier when a second substitution is performed either at $\mathrm{CuO}_{2}$ planes or at other planes ( $\mathrm{Sr}$ or $\mathrm{Ca}$ ). The role of lead appears also in suppressing the superstructure [6]. Chemical doping in high $\mathrm{T}_{\mathrm{c}}$ superconducting cuprates (HTSC) have been reported at many studies [7, 8]. The primary purpose of the authors was to improve superconducting properties of their compounds [9-12]. The rareearth element in many HTSC families of compounds plays an important role for the stabilization of the structure [7, 13, 14]. For more significant results, small concentrations of doping atoms should be considered. After the discovery of the Bi-2212 $\left(\mathrm{Bi}_{2} \mathrm{Sr}_{2} \mathrm{CaCu}_{2} \mathrm{O}_{8+\mathrm{d}}\right)$ superconducting phase $[3,5]$, the effect of doping by alkaline elements was studied [15-17]. This kind of doping results in changing the unit crystallographic cell parameters 
accompanied by a lowering of the phase formation temperature caused by the flux action of the alkaline element, for example: doping by potassium on the $\mathrm{Sr}$ site results in a contraction of the $c$ axis parameter [16]. The decrease of oxygen content explains the generally observed enhancement of $\mathrm{T}_{\mathrm{c}}$ [18]. More recently, in polycrystalline bulks of $\mathrm{Bi}_{2} \mathrm{Sr}_{2} \mathrm{Ca}_{1-\mathrm{x}} \mathrm{K}_{\mathrm{x}} \mathrm{Cu}_{2} \mathrm{O}_{8+\mathrm{d}}$, ac susceptibility measurement revealed the optimization of intergrain connections. An improvement of critical current density has been noticed [19]. Addition of potassium allowed also a faster growth rate of $\mathrm{Bi}-2212$ whiskers [20]. In this paper, we study the effect on the $\mathrm{Bi}(\mathrm{Pb})-2212$ phase at low rate of potassium doping by substitution or addition.

\section{Experimental}

Samples of $\mathrm{Bi}_{1.5} \mathrm{~Pb}_{0.5}\left(\mathrm{Sr}_{1.8-\mathrm{x}} \mathrm{K}_{\mathrm{x}}\right) \mathrm{CaCu}_{2} \mathrm{O}_{8+\mathrm{d}}$ $(0 \leqslant x \leqslant 0.05)$ were prepared with the usual method of solid state reaction using high grade purity powders of $\mathrm{Bi}_{2} \mathrm{O}_{3}, \mathrm{SrCO}_{3}, \mathrm{CaCO}_{3}, \mathrm{PbO}$, $\mathrm{CuO}$ and $\mathrm{KOH}$. The starting mixtures were calcined at $800{ }^{\circ} \mathrm{C}$ for $30 \mathrm{~h}$. After that, the obtained powders were ground and pressed into pellet shape $(13 \mathrm{~mm}$ in diameter and $1 \mathrm{~mm}$ thickness) under pressure of $5 \mathrm{ton} / \mathrm{cm}^{2}$ and finally sintered at $850{ }^{\circ} \mathrm{C}$ for $40 \mathrm{~h}$. Preparation of samples of $\mathrm{Bi}_{1.5} \mathrm{~Pb}_{0.5} \mathrm{Sr}_{1.8} \mathrm{CaCu}_{2} \mathrm{O}_{8+\mathrm{d}} \mathrm{K}_{\mathrm{x}}(0 \leqslant \mathrm{x} \leqslant 0.05$; addition method) follows the same route as in substitution but without $\mathrm{KOH}$, which is added only after calcination. $\mathrm{x}$ : corresponds to the weight fraction of the powder of the free $\mathrm{K} \mathrm{Bi}(\mathrm{Pb})-2212$ phase obtained after calcination. Obtained samples were characterized by X-ray diffraction (XRD) using $\mathrm{CuK} \alpha$ radiation and scanning electron microscopy (SEM) [21]. Indexation of XRD patterns and determination of lattice parameters of samples have been done using CELREF software. Resistivity of samples was measured in temperature range $10 \mathrm{~K}$ to $125 \mathrm{~K}$, on a closed cycle helium refrigerator (Cryodine CTI-Cryogenics) using a standard DC four-probe technique with a constant current of $5 \mathrm{~mA}$ at Physics Department of Abbant Izzet Baysal University of Bolu in Turkey. The magnetic measurements have been performed by means of a 9 Tesla Quantum Design PPMS (Physical
Properties Measurement System) equipped with a Vibrating Sample Magnetometer (VSM) option at Physics Department of University of Salerno in Italy. It is worth to underline that, before each measurement, the residual magnetic field entrapped in the superconducting magnet was reduced below $1 \times 10^{-4} \mathrm{~T}[22,23]$. The $\mathrm{M}(\mathrm{T})$ and $\mathrm{M}(\mathrm{H})$ measurements of magnetization as a function of the temperature and the magnetic field, respectively, were performed using the typical procedures [24-26]. In particular, the $\mathrm{M}(\mathrm{T})$ measurements were performed in zero field cooling (ZFC) and field cooling (FC) conditions. More precisely, the sample was first cooled down to $40 \mathrm{~K}$ in the absence of field, then a magnetic field of 0.002 Tesla was switched on and the data were acquired for increasing temperature (ZFC) reaching the room temperature $120 \mathrm{~K}$. After that, the sample was cooled down again and FC magnetization was acquired in the presence of field. For $\mathrm{M}(\mathrm{H})$ measurements, the sample was first thermally stabilized to $4.2 \mathrm{~K}$ in the absence of magnetic field. Then, the field was ramped to reach +9 $\mathrm{T}$, then back to $-9 \mathrm{~T}$, and finally to $+9 \mathrm{~T}$ again, in order to acquire the complete $\mathrm{M}(\mathrm{H})$ loop.

\section{Results and discussion}

In our previous work, both substitution and addition affect the intensity of main peak's $(\mathrm{Bi}, \mathrm{Pb})$ 2212 [21]. Traces of parasitic phases Bi-2201 and /or $\mathrm{Ca}_{2} \mathrm{PbO}_{4}$ are present in all the samples. In SEM micrographs, the typical lamellar structure of HCTS is present. We can notice that the addition of $\mathrm{K}$ gives a faster growth rate of $\mathrm{Bi}-2212$ whiskers [21]. The ionic radius of $\mathrm{K}^{+}$ion is $1.38 \AA$ when its coordination number is 6 and reaches $1.51 \AA$ for a coordination number of 8 [27]. The $\mathrm{Sr}^{2+}$ one is $1.18 \AA$ and $1.26 \AA$ respectively for the same coordination numbers. Thus, $c$ axis may increase when K substitutes on $\mathrm{Sr}$ site. The observed contraction of $\mathrm{c}$ axis may be due to a transfer of charges between the $\mathrm{CuO}_{2}$ planes resulting from the difference of valence between $\mathrm{K}^{+}$and $\mathrm{Sr}^{2+}$ ions. When $\mathrm{K}$ is added to the $\mathrm{Bi}(\mathrm{Pb})-2212$ phase $c$ axis increases for most of the samples suggesting that $\mathrm{K}$ substitutes on the $\mathrm{Ca}$ site where the ionic radius of $\mathrm{Ca}^{2+}$ is $1.12 \AA$ (coordination number of 
8). The same kind of charge transfer is present but giving a different result when the site changes. The difference of behaviour between addition and substitution also appears in the variation of the orthorhombic strain $(b-a) /(a+b)$ versus the content $x$ of $\mathrm{K}$ shown in Table 1 and Table 2 where the variations of $\mathrm{c}$ axis are reported. The effect of $\mathrm{K}$ on the orthorhombic strain is higher for substitution where its increase corresponds to a decrease of parameter $\mathrm{c}$. This means that substitution by potassium on outer plane (the $\mathrm{Sr}$ site) promotes the displacement of oxygen ions toward the $\mathrm{CuO}_{2}$ planes. The excess of charge in these planes increases the Jahn Teller distortion effect on the oxygen octahedron surrounding the $\mathrm{Cu}^{2+}$ ion. This excess of charge also causes the contraction of the $\mathrm{c}$ axis. With the addition of potassium, the behaviour of the orthorhombic strain is contrary, and a possible substitution on $\mathrm{Ca}$ site instead of $\mathrm{Sr}$ site is considered.

A standard four-probe technique measures the electrical resistivity. Fig. 1 shows its variation as a function of temperature and doping. The results show the typical rapid resistive transition of superconductors where $T_{c}$ is determined. In Fig. 1(b), the values of resistivity of sample with $\mathrm{x}=0.01$ are divided by 20 in order to get all the curves together.

Table 3 and Table 4 present the critical temperatures $\mathrm{T}_{\mathrm{c}}^{\text {onset }}$ (beginning of the transition from the normal state to the superconducting one) and $\mathrm{T}_{\mathrm{c}}^{\mathrm{off}}$ (end of the state corresponding to $\mathrm{R}=0$ ) of the samples. $T_{c}^{\text {onset }}$ for all the samples obtained by addition or substitution is lower than the $\mathrm{K}$ free sample. Overall oxygen content and the disorder in $\mathrm{CuO}_{2}$ planes [28, 29] are mechanisms responsible for variation of $\mathrm{T}_{\mathrm{c}}^{\text {onset }}$. For substitution, $\mathrm{T}_{\mathrm{c}}^{\mathrm{onset}}$ is maximum at $\mathrm{x}=0.01$ and corresponds to a minimum of orthorhombic strain and a high value of $\mathrm{c}$ axis. Substitution by potassium at the $\mathrm{Sr}$ site leads to a decrease of $\mathrm{T}_{\mathrm{c}}^{\text {onset }}$. Similar results were found by T.H. Duc et al. [12], the authors found that both transition temperatures $\mathrm{T}_{\mathrm{c}}^{\text {onset }}$ and $\mathrm{T}_{\mathrm{c}}^{\text {off }}$ were decreased with bulk of $\mathrm{Bi}_{1.6} \mathrm{~Pb}_{0.4} \mathrm{Sr}_{2-\mathrm{x}} \mathrm{K}_{\mathrm{x}} \mathrm{Ca}_{2} \mathrm{Cu}_{3} \mathrm{O}_{10+\mathrm{d}}$ where $\mathrm{x}=0.00$, $0.04,0.08$ and 0.1 ); only in this study, two superconducting phases of $\mathrm{Bi}-2223$ and $\mathrm{Bi}-2212$
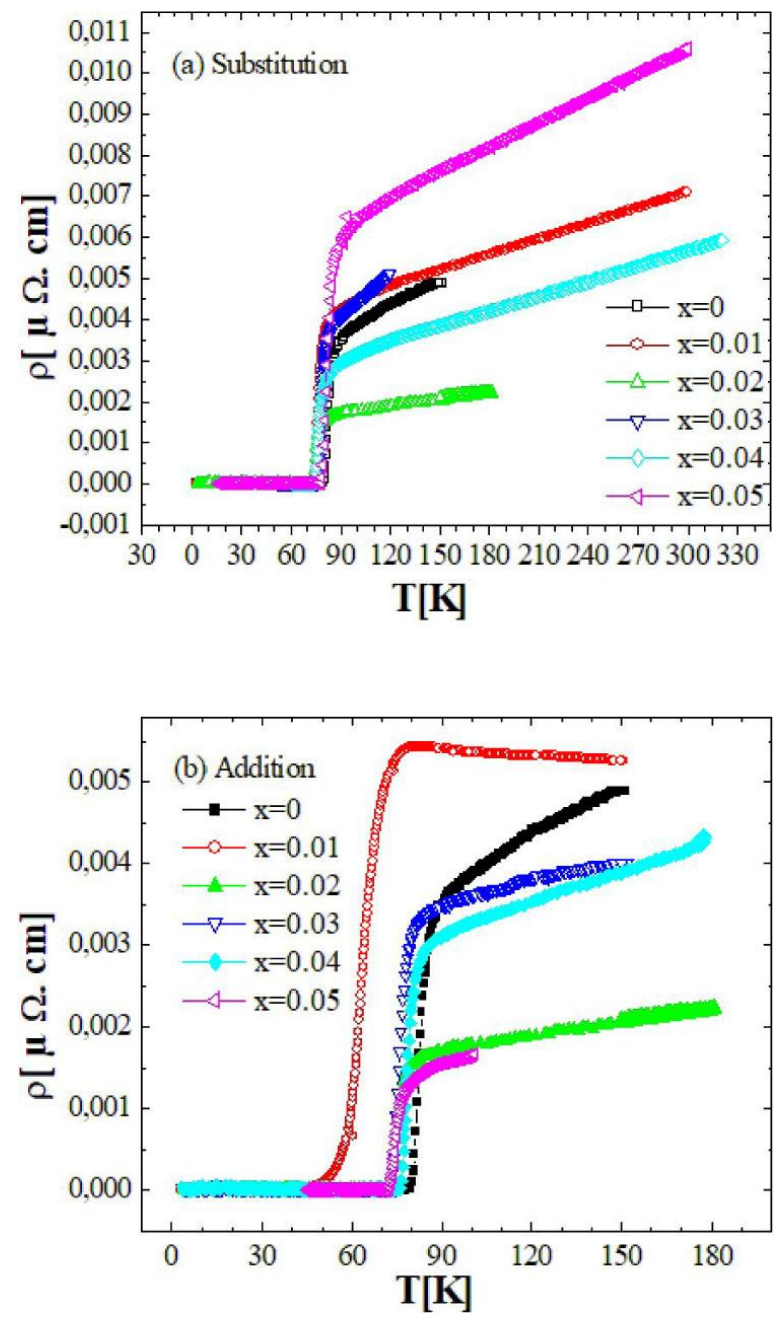

Fig. 1. Resistivity versus temperature curves obtained for samples doped by potassium substitution (a) and addition (b).

were formed. When a second substitution is used other than lead $(\mathrm{Pb}), \mathrm{T}_{\mathrm{c}}$ seems to behave otherwise. In case of superconducting $\mathrm{K}-\mathrm{Na}$ co-doped $\mathrm{Bi}_{2} \mathrm{Sr}_{2} \mathrm{~K}_{\mathrm{x}} \mathrm{Ca}_{1} \mathrm{Cu}_{1.75} \mathrm{Na}_{0.25} \mathrm{O}_{\mathrm{y}}(\mathrm{x}=0,0.05,0.1$ and $0.25)$ ceramics [17], the results show that $\mathrm{T}_{\mathrm{c}}^{\text {onset }}$ values are gradually increasing as $\mathrm{K}$ content is increased. Our results are explained by the excess of charge in $\mathrm{CuO}_{2}$ planes due to the oxygen octahedron surrounding the $\mathrm{Cu}^{+2}$ ion (Jahn Teller distortion effect); this causes a contraction of the $\mathrm{c}$ axis thus a decrease of $T_{c}$.

The used $\mathrm{x}$ rate of substitution of $\mathrm{K}$ is very low, its effect on the $\operatorname{Bi}(\mathrm{Pb})-2212$ phase is not the same as on the $\mathrm{Bi}-2212$ phase where higher rates were 
Table 1. Variations of the orthorhombic strain $(b-a) /(a+b)$ versus $x$ content of potassium for samples obtained by substitution and addition [21].

\begin{tabular}{ccccccc}
\hline $\mathrm{x}$ & 0 & 0.01 & 0.02 & 0.03 & 0.04 & 0.05 \\
\hline \hline$(\mathrm{b}-\mathrm{a}) /(\mathrm{a}+\mathrm{b}) \times 10^{3}$ substitution & 0.00413 & 0.00374 & 0.00552 & 0.00501 & 0.00375 & 0.00452 \\
$(\mathrm{~b}-\mathrm{a}) /(\mathrm{a}+\mathrm{b}) \times 10^{3}$ addition & 0.00413 & 0.00412 & 0.00361 & 0.00429 & 0.00269 & 0.00439 \\
\hline
\end{tabular}

Table 2. Variations of lattice parameter $\mathrm{c}$ versus $\mathrm{x}$ content of potassium for samples obtained by substitution and addition [21].

\begin{tabular}{|c|c|c|c|c|c|c|}
\hline $\mathrm{x}$ & 0 & 0.01 & 0.02 & 0.03 & 0.04 & 0.05 \\
\hline$c[\AA ̊ \cap]$ substitution & 30.6841 & 30.71 & 30.5705 & 30.5124 & 30.6947 & 30.7269 \\
\hline $\mathrm{c}[\AA] \mathrm{A}$ addition & 30.6841 & 30.7985 & 30.7479 & 30.7203 & 30.6479 & 30.7074 \\
\hline
\end{tabular}

used [16]. A decrease of the $T_{c}$ is observed contrary to the increase observed in the Bi-2212 phase. Table 4 gives values of $\mathrm{T}_{\mathrm{c}}^{\text {off }}$ for all the samples. The results show that $T_{c}^{\text {off }}$ for samples obtained by addition, is lower than the pure sample with a minimum at $\mathrm{x}=0.01$.

For those obtained by substitution, the same behaviour is observed and the $\mathrm{T}_{\mathrm{c}}^{\text {off }}$ value corresponding to $\mathrm{x}=0.01$ is improved. $\mathrm{T}_{\mathrm{c}}^{\mathrm{off}}$ indicates the beginning of the flux creep of the vortices and gives information about the quality of the pinning in the sample. The critical temperature $\mathrm{T}_{\mathrm{c}}$ of the samples is also determined from the $\mathrm{M}(\mathrm{T})$ measurements in zero field cooling (ZFC) and field cooling (FC) conditions with an applied field of $0.002 \mathrm{~T}$ (see Fig. 2(a)-(b)). In this case, $T_{c}$ is equal to the temperature corresponding to the onset of the ZFC magnetization drop as shown in Fig. 2(a)-(b). From the enlargement of the curve in the region of the superconducting transition, we can notice that $T_{c}$ reported values are consistent with those obtained by measurement of resistivity versus temperature. The difference $\Delta \mathrm{M}$, between $60 \mathrm{~K}$ and $90 \mathrm{~K}$ of the ZFC and FC branches (see Fig. 3(a)-(b)), gives the irreversibility temperature $T_{\text {irr }}$ of the samples. $T_{\text {irr }}$ corresponds to the value of temperature where $\Delta \mathrm{M}$ becomes equal to zero corresponding to the $\mathrm{ZFC}$ and FC overlap [30].

Fig. 4 reports $T_{c}$ and $T_{\text {irr }}$ values for the $K$ doped samples prepared by substitution (Fig. 4(a)) and by addition (Fig. 4(b)). $\mathrm{T}_{\text {irr }}$ values are lower than $\mathrm{T}_{\mathrm{c}}$ while the difference between the two parameters for the same concentrations is not significant and seems to be the same except for $\mathrm{x}=0.01$, which appears more significant. Addition of $\mathrm{K}$ causes a decrease in both $T_{c}$ and $T_{\text {irr }}$, more importantly in the $\mathrm{x}=0.01$ sample. On the other hand, substitution by $\mathrm{K}$ causes a quasi-linear decrease of $\mathrm{T}_{\text {irr }}$ until $\mathrm{x}=0.04$. At $\mathrm{x}=0.05$, the decrease is significantly lower giving a value near to that of the undoped sample. $\mathrm{T}_{\mathrm{c}}$ is improved for $\mathrm{x}=0.01$ but it decreases for the other values of $\mathrm{x}$, except for $\mathrm{x}=0.01, \mathbf{T}_{c}$ has a similar behaviour as $\mathrm{T}_{\mathrm{c}}^{\text {onset }}$ obtained by transport measurement.

Fig. 5 shows, for the $\mathrm{K}$ doped samples by substitution (Fig. 5(a)) and addition (Fig. 5(b)), the magnetic hysteresis loops measured at $\mathrm{T}=4.2 \mathrm{~K}$ with the applied field $\mathrm{H}$ parallel to the $\mathrm{c}$ axis $(\mathrm{H}|| \mathrm{c})$. Use of the Bean critical state model $[31,32]$ allows to extract the critical current density $J_{c}$ from the $\mathrm{M}(\mathrm{H})$ curves. The formula used is:

$$
\begin{gathered}
J c=20 \Delta M H /[b(1-b / 3 a)] \\
\Delta M H=M d n-M u p
\end{gathered}
$$

Where Mdn is the magnetization measured for decreasing, Mup for increasing, the applied magnetic field. $\mathrm{a}$ and $\mathrm{b}$ are the lengths (in $\mathrm{cm}$ ) characterizing the cross section of the sample perpendicular to the applied field $(\mathrm{H}|| \mathrm{c})$.

Fig. 6 reports $J_{c}$ variations versus the applied field $\mathrm{H}$ for the $\mathrm{K}$ doped samples by substitution (a) and addition (b). Except for $\mathrm{x}=0.01$ doped by addition, both methods enhance $\mathbf{J}_{c}$. Highest $\mathrm{J}_{\mathrm{c}}$ is obtained in sample doped by substitution 
Table 3. $\mathrm{T}_{\mathrm{c}}^{\text {onset }}$ of the samples.

\begin{tabular}{ccccccc}
\hline $\mathrm{x}$ & 0 & 0.01 & 0.02 & 0.03 & 0.04 & 0.05 \\
\hline \hline $\mathrm{T}_{\mathrm{c}}^{\text {onset }}$ substitution $[\mathrm{K}]$ & 82.19 & 81.94 & 79.03 & 79.14 & 75.28 & 80.4 \\
$\mathrm{~T}_{\mathrm{c}}^{\text {onset }}$ addition $[\mathrm{K}]$ & 82.19 & 70.85 & 78.3 & 79.38 & 80.31 & 78.72 \\
\hline
\end{tabular}

Table 4. $T_{c}^{\text {off }}$ of the samples.

\begin{tabular}{ccccccc}
\hline $\mathrm{x}$ & 0 & 0.01 & 0.02 & 0.03 & 0.04 & 0.05 \\
\hline \hline $\mathrm{T}_{\mathrm{c}}^{\text {off }}$ substitution $[\mathrm{K}]$ & 79.27 & 73.73 & 74.56 & 75.71 & 74.43 & 77.68 \\
$\mathrm{~T}_{\mathrm{c}}^{\text {off }}$ addition $[\mathrm{K}]$ & 79.27 & 47.31 & 73.78 & 73.56 & 76.13 & 72.05 \\
\hline
\end{tabular}
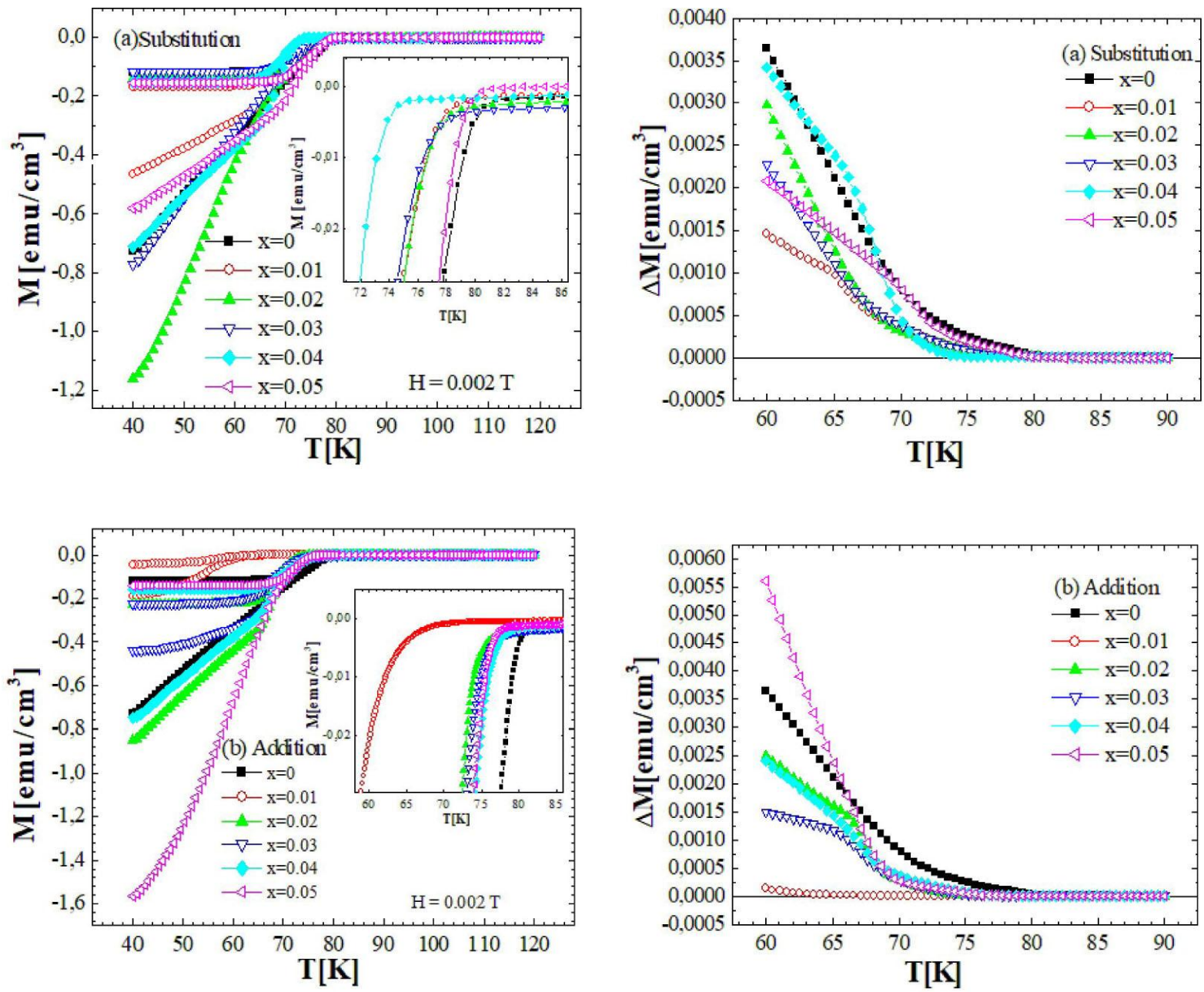

Fig. 2. Magnetization as the function of temperature $\mathrm{M}(\mathrm{T})$ using ZFC-FC procedure for the $\mathrm{K}$ doped samples by substitution (a) and by addition (b). The applied field is 0.002 Tesla. The insets show a magnification of the region near the superconducting transition.

Fig. 3. Variation of $\Delta \mathrm{M}$ with temperature for samples obtained by substitution (a) and addition (b) of potassium 

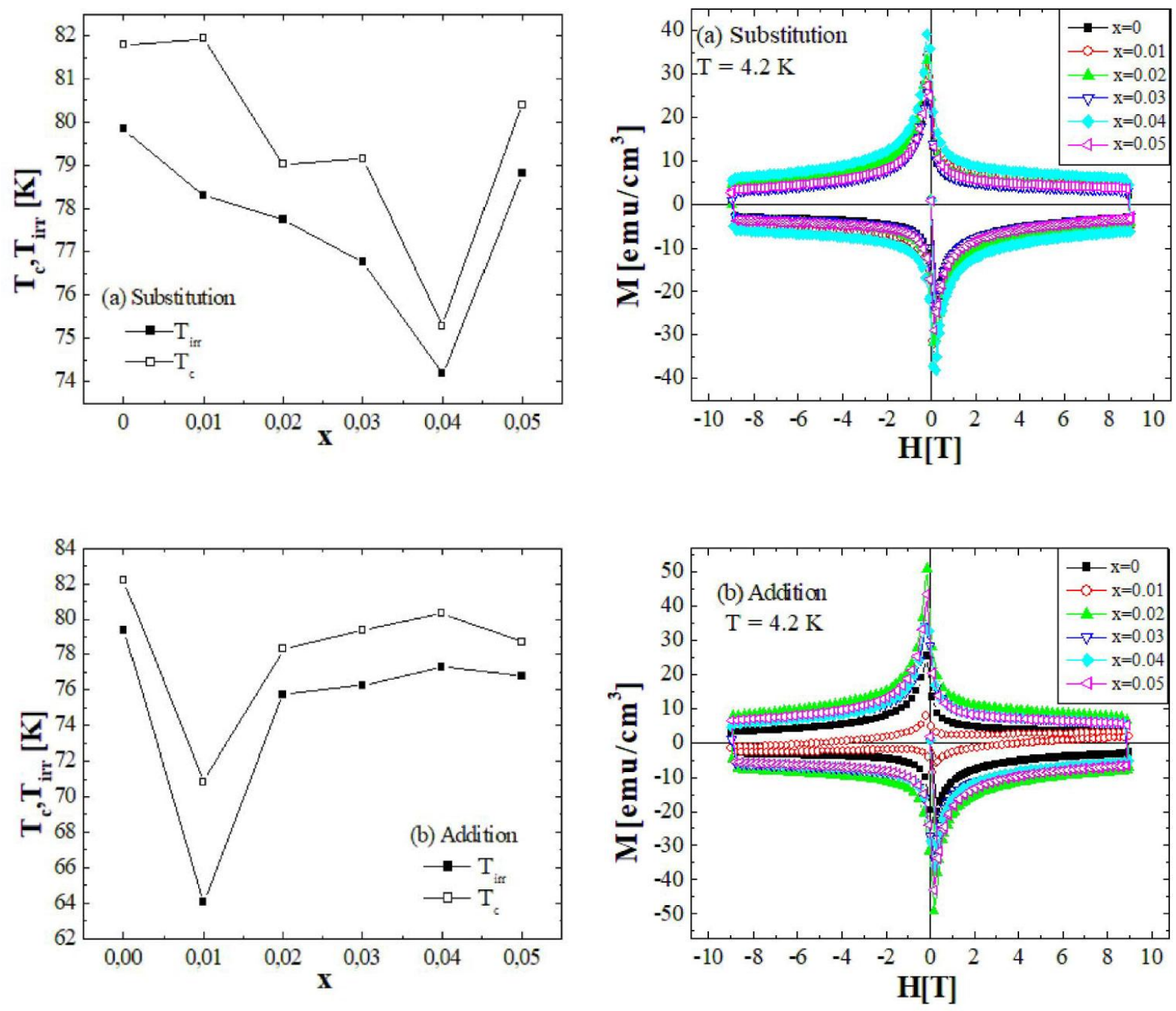

Fig. 4. $\mathrm{T}_{\mathrm{c}}$ and $T_{\mathrm{irr}}$ values obtained for $\mathrm{K}$ doped samples by substitution (a) and addition (b) of potassium

with $\mathrm{x}=0.04$ and sample doped by addition with $\mathrm{x}=0.02$. Addition of $\mathrm{K}$ gives higher values of $\mathrm{J}_{\mathrm{c}}$ reaching a maximum more than two times the undoped one. In Bi based superconducting ceramics, the structural properties are beside the anisotropy of physical properties the main factor governing the behaviour of $\mathrm{J}_{\mathrm{c}}$. Improvement of critical current density is due to the enhancement of flux pinning properties [33]. This depends at its turn on structure for intrinsic pinning and grain boundaries for pinning centres (low angle grain boundaries can act as pinning centres). Effective pinning centres are created by doping impurities, of the order of coherence length, in the system. This will lead to an improvement of flux pinning properties of

Fig. 5. Magnetic hysteresis loops measured at $\mathrm{T}=4.2 \mathrm{~K}$ for the $\mathrm{K}$ doped samples by substitution (a) and addition (b).

the Bi system. Impurities chosen for flux pinning should not deteriorate the superconducting properties $[34,35]$. Jc depends also on grain size and orientation, which control the size of superconducting current loops $[19,36]$. The lowest value of $\mathbf{J}_{\mathrm{c}}$ is obtained in the sample doped by addition with $\mathrm{x}=0.01$.

\section{Conclusion}

In the present work, samples of $\mathrm{Bi}(\mathrm{Pb}) 2212$ are doped by potassium using two methods: substitution and addition. XRD and SEM analysis shows 

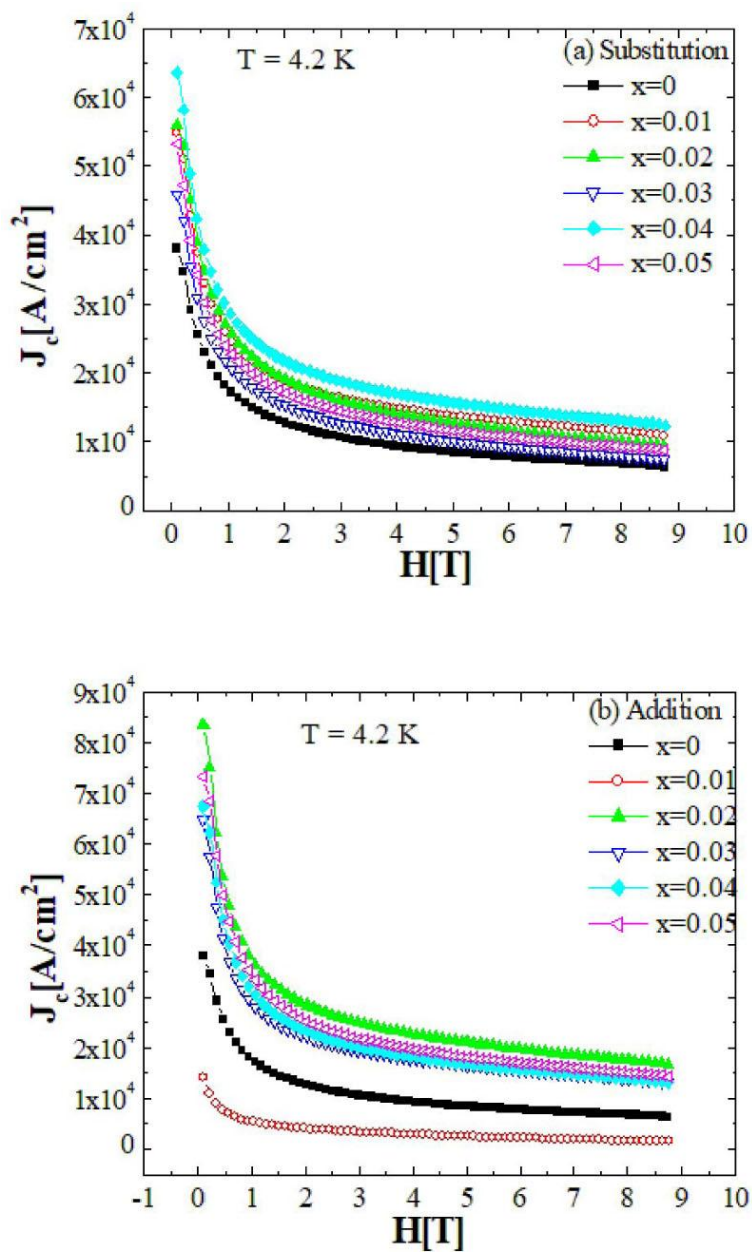

Fig. 6. Magnetic field dependence, at $\mathrm{T}=4.2 \mathrm{~K}$, of critical current density $\mathrm{J}_{\mathrm{c}}$ for $\mathrm{K}$ doped samples with substitution (a) and addition (b).

that substitution by $\mathrm{K}$ enhances the texture, while for addition, this effect is obtained only for a lower rate of $\mathrm{K}$ [21]. Resistivity measurements show a decrease of $\mathrm{T}_{\mathrm{c}}^{\text {onset }}$ and $\mathrm{T}_{\mathrm{c}}^{\text {off }}$ for both methods. The $\mathrm{K}$ doping by substitution may increase the incorporation of oxygen in the structure; this will reduce the $\mathrm{Cu}$ valence and consequently a degradation of $\mathrm{T}_{\mathrm{c}}^{\text {onset }}$.

Magnetic measurements show an improvement of the critical current density for both methods. The enhance of $\mathrm{J}_{\mathrm{c}}$ is greater for the samples obtained by addition and it reaches a maximum (more than two times the un-doped one). This effect is a result of the improvement of the texture, which give a better grain orientation and the higher grain size observed by SEM [21]. The results have shown that better properties are obtained when potassium is added with a possible substitution at the calcium site instead of strontium site.

For practical application, potassium doping by addition seems a better way to improve superconducting properties.

\section{Acknowledgements}

The authors thank University of Salerno and Abbant Izzet Baysal University for material and analytical supports.

\section{References}

[1] Bednorz JG, Müller KA, Possible high $\mathrm{T}_{c}$ superconductivity in the $\mathrm{Ba}-\mathrm{La}-\mathrm{Cu}-\mathrm{O}$ system, Z. Phys. B-Cond. Mat., 1986;64:189-93. https://doi.org/10.1007/ BF01303701

[2] Michel C, Hervieu M, Borel MM, Grandin A, Deslandes F, Provost J, Raveau B, Z. Phys. B-Cond. Mat., 1987;68:421-3. https://doi.org/10.1007/ BF01471071

[3] Maeda H, Tanaka Y, Fukutomi M, Asano T. A New HighT $_{c}$ Oxide Superconductor without a Rare Earth Element. Jpn J Appl Phys., 1988;27(Part 2, No. 2):L209-10. https://doi.org/10.1143/JJAP.27.L209

[4] Tarascon JM, McKinnon WR, Barboux P, Hwang DM, Bagley BG, Greene LH, et al. Preparation, structure, and properties of the superconducting compound series Bi2Sr2Can-1CunOy with $\mathrm{n}=1$, 2, and 3. Phys Rev B Condens Matter. 1988 Nov;38(13):888592. https://doi.org/10.1103/PhysRevB.38. 8885PMID : 9945668

[5] Von Schnering HG, Angew. Chem., 100 (1988), 604-607. Angew. Chem. Int. Edit. Engl., 1988;27:574-6 https : //doi.org/10.1002/anie.198805741

[6] Liu J, Zhao L, Gao Q, Ai P, Zhang L, Xie $\mathrm{T}$, et al. Evolution of incommensurate superstructure and electronic structure with $\mathrm{Pb}$ substitution in $\left(\mathrm{Bi}_{2-x} \mathrm{~Pb}_{x}\right) \mathrm{Sr}_{2} \mathrm{CaCu}_{2} \mathrm{O}_{8}+\delta$ superconductors. Chin Phys B., 2019;28(7):077403. https://doi .org/10.1088/ 1674-1056/28/7/077403

[7] Wu HY, Ruan QK, Yin J, Huang SL, Lv ZM, Li $\mathrm{M}$, et al. Effect of $\mathrm{K}$ and $\mathrm{Nd}$ substitutions on superconductivity of $\mathrm{Bi} 2223$ superconductors. Supercond Sci Technol. 2007;20(12):1189-92. https:// doi.org/10.1088/0953-2048/20/12/019

[8] Sekhar MC, Krishna BG, Reddy RR, Reddy PV, Suryanarayana SV. Suryanarayana SV. Elastic anomalies in sodium-doped Bi-2212 single-phase HTSC materials. Supercond Sci Technol. 1996;9(1):29-33. https:// doi.org/10.1088/0953-2048/9/1/004

[9] Biju A, Vinod K, Aloysius RP, Syamaprasad U. Improved superconducting properties by La addition in $(\mathrm{Bi}, \mathrm{Pb})-2212$ bulk superconductor. J Alloys Compd. 2007;431(1-2):49-55. https ://doi .org/10. 1016/j.jallcom.2006.05.080 
[10] Sedky A. On the influence of rare-earth substitution for $\mathrm{Ca}$ in $\mathrm{Bi}(\mathrm{Pb}): 2212$ superconducting system. Physica C. 2008;468(14):1041-6. https://doi.org/10. $1016 / j$.physc. 2008.05.004

[11] Vinu S, Sarun PM, Shabna R, Biju A, Syamaprasad U. Microstructure and transport properties of $\mathrm{Bi1}$.6Pb0.5Sr2-xLuxCa1.1Cu2.108+ $\delta$ superconductor. Mater Chem Phys. 2010;119(1-2):135-9. https:// doi.org/10.1016/j.matchemphys.2009.08.049

[12] Duc TH, An PT, Anh DTK, Linh VH, Ha PH, Man NK, Vnu J. Effect of K Substitutions on Structural and Superconducting Properties in $\mathrm{Bi}_{1.6} \mathrm{~Pb}_{0.4} \mathrm{Sr}_{2-x} \mathrm{~K}_{x} \mathrm{Ca}_{2} \mathrm{Cu}_{3} \mathrm{O}_{10+\delta}$ Compounds. Sci.:Math.- Phys. 2019;35:42-9. https: //doi.org/10.25073/2588-1124/vnumap. 4324

[13] Hawa JS, Azhan H, Yahya SYS, Azman K, Hidayah HN, Norazidah AW. Influence of $\mathrm{Na}, \mathrm{Mg}$ and $\mathrm{Yb}$ Substitution for $\mathrm{Ca}$ in $\mathrm{Bi}(\mathrm{Pb})-2223$ Superconductor. Adv Mat Res. 2012;501:289-93. https://doi.org/10.4028/www . scientific.net/AMR.501.289

[14] Vinu S, Sarun PM, Biju A, Shabna R, Guruswamy $\mathrm{P}$, Symaprasad U. The effect of substitution of $\mathrm{Eu}$ on the critical current density and flux pinning properties of $(\mathrm{Bi}, \mathrm{Pb})-2212$ superconductor. Supercond Sci Technol. 2008;21(4):045001. https://doi.org/10. 1088/0953-2048/21/4/045001

[15] Koike Y, Iwabuchi Y, Hosoya S, Kobayashi N, Fukase $\mathrm{T}$. Correlation between $\mathrm{Tc}$ and hole concentration in the cation-substituted $\mathrm{Bi} 2 \mathrm{Sr} 2 \mathrm{CaCu} 2 \mathrm{O} 8+\delta$ system. Physica C. 1989;159(1-2):105-10. https://doi.org/10. 1016/0921-4534 (89) 90110-X

[16] Gopala Krishna B, Ravi Chandra G, Suryanarayana SV. Potassium substitution in the $\mathrm{Bi} 2 \mathrm{Sr} 2 \mathrm{CaCu} 2 \mathrm{Oy}$ superconductor. Mater Sci Eng B. 1994;25:153-8. https: //doi.org/10.1016/0921-5107(94)90217-8

[17] Kır ME, Özkurt B, Aytekin ME. The effect of K-na co-doping on the formation and particle size of $\mathrm{Bi}$ 2212 phase. Physica B. 2016;490:79-85. https:// doi.org/10.1016/j.physb.2016.03.016

[18] Dou SX, Liu HK, Wu WM, Wang WX, Sorell CC, Winn R, et al. Melt processing of alkali element doped Bi2Sr2CaCu2O8. Physica C. 1990;172(3-4):295303. https://doi.org/10.1016/0921-4534(90) 90620-T

[19] Zhang S, Li C, Hao Q, Ma X, Lu T, Zhang P. Optimization of $\mathrm{Bi}-2212$ high temperature superconductors by potassium substitution. Supercond Sci Technol. 2015 Apr;28(4):045014. https://doi.org/10. 1088/0953-2048/28/4/045014

[20] Yamada M, Hosi N, Kambe S. Addition of Ag, $\mathrm{Pb}, \mathrm{K}$, or $\mathrm{Li}$ to $\mathrm{Bi} 2 \mathrm{Sr} 2 \mathrm{CaCu} 2 \mathrm{Oy}$ whisker. Physica C. 2002;378-381:152-4. https://doi.org/10. 1016/S0921-4534(02)01401-6

[21] Belala K, Mosbah MF. Effects of K doping on structural and superconducting properties of $\mathrm{Bi} 1.5 \mathrm{~Pb} 0.5 \mathrm{Sr} 1.8 \mathrm{CaCu} 2 \mathrm{O} 8+\delta \quad \mathrm{com}$ pounds. AIP Conf. Proc., 2013;1569:95-9. https://doi.org/10.1063/1.4849236

[22] Galluzzi A, Buchkov K, Nazarova E, Tomov V, Grimaldi G, Leo A, et al. Transport properties and high upper critical field of a $\mathrm{Fe}(\mathrm{Se}, \mathrm{Te})$ iron based superconductor. Eur Phys J Spec Top., 2019;228(3):725-31. https : //doi.org/10.1140/epjst/e2019-800169-5

[23] Galluzzi A, Buchkov K, Nazarova E, Tomov V, Grimaldi G, Leo A, et al. Nanotechnology. 2019 Jun;30(25):254001. https://doi.org/10.1088/ 1361-6528/ab0c23PMID : 30831561

[24] Galluzzi A, Mancusi D, Cirillo C, Attanasio C, Pace S, Polichetti M. Determination of the Transition Temperature of a Weak Ferromagnetic Thin Film by Means of an Evolution of the Method Based on the Arrott Plots. J Supercond Nov Magn. 2018;31(4):1127-32. https: //doi.org/10.1007/s10948-017-4281-4

[25] Galluzzi A, Buchkov K, Tomov V, Nazarova E, Grimaldi $\mathrm{G}$, Leo A, et al. Evidence of pinning crossover and the role of twin boundaries in the peak effect in FeSeTe iron based superconductor. Supercond Sci Technol. 2018;31(1):015014. https://doi.org/10. 1088/1361-6668/aa9802

[26] Galluzzi A, Buchkov K, Tomov V, Nazarova E, Kovacheva D, Leo A, et al. Mixed state properties of iron based $\mathrm{Fe}(\mathrm{Se}, \mathrm{Te})$ superconductor fabricated by Bridgman and by self-flux methods. J Appl Phys. 2018;123(23):233904. https://doi.org/10. 1063/1.5032202

[27] Shannon RD. Revised effective ionic radii and systematic studies of interatomic distances in halides and chalcogenides. Acta Crystallogr A. 1976;32(5):751-67. https://doi.org/10.1107/S0567739476001551

[28] Awana VP, Narlikar AV. Role of calcium in suppressing the superconductivity of $\mathrm{Y} 1-\mathrm{xCaxBa} 2 \mathrm{Cu} 3 \mathrm{O} 7-$ delta. Phys Rev B Condens Matter. 1994 Mar;49(9):6353-5. https://doi.org/10.1103/PhysRevB.49. 6353PMID : 10011630

[29] Awana VP, Malik SK, Yelon WB. Structural aspects and superconductivity in oxygen-deficient Y1-xCaxBa2Cu3O7-y (y $\approx 0.3)$ system A neutrondiffraction study. Physica C. 1996;262(3-4):272-8. https://doi.org/10.1016/0921-4534(96) 00213-4

[30] Vieira VN, Riegel IC, Schaf J. Granular superconductivity in a Ca-doped $\mathrm{Y} \mathrm{Ba} 2 \mathrm{Cu} 3 \mathrm{O} 7-\delta$ single crystal: role of divalent impurities and the effect of applied fields on the grain coupling. Phys Rev B Condens Matter Mater Phys. 2007;76(2):024518. https://doi.org/ 10.1103/PhysRevB.76.024518

[31] Bean CP. Magnetization of Hard Superconductors. Phys Rev Lett. 1962;8(6):250-3. https://doi.org/ 10.1103/PhysRevLett.8.250

[32] Bean CP. Magnetization of High-Field Superconductors. Rev Mod Phys. 1964;36(1):31-9. https://doi.org/ 10.1103/RevModPhys.36.31

[33] Shigemori M, Okabe T, Uchida S, Sugioka T, Shimoyama J, Horii S, et al. Enhanced flux pinning 
properties of $\mathrm{Bi}(\mathrm{Pb}) 2212$ single crystals. Physica $C$. 2004;408-410:40-1. https ://doi.org/10.1016/j. physc. 2004.02.027

[34] Biju A, Kumar RG, Aloysius RP, Syamaprasad U. Flux pinning properties of rare earth modified $(\mathrm{Bi}, \mathrm{Pb})-2212$ superconductors. Supercond Sci Technol. 2006;19(8):854-9. https://doi.org/10.1088/ 0953-2048/19/8/029

[35] Biju A, Sarun PM, Aloysius RP, Syamaprasad U. Flux pinning properties of $\mathrm{Yb}$ substituted $(\mathrm{Bi}, \mathrm{Pb})-2212$ superconductor. J Alloys Compd. 2008;454(1-2):46-
51. https://doi.org/10.1016/j.jallcom. 2006. 12.100

[36] Senoussi S. Review of the critical current densities and magnetic irreversibilities in high $\mathrm{T}_{c}$ superconductors. $J$ Phys III. 1992;2(7):1041-257. https : //doi .org/10. 1051/jp3: 1992102

Received 22-02-2021

Accepted 22-02-2021 